\title{
ESTAGIAR: ESTÁGIO DE LÍNGUA PORTUGUESA E LITERATURA EM EVENTO
}

\author{
NÚBIO DELANNE FERRAZ MAFRA (UEL) ${ }^{1}$ \\ https://orcid.org/0000-0002-9658-691x \\ SHEILA OLIVEIRA LIMA (UEL) $)^{2}$ \\ https://orcid.org/0000-0002-0993-8228
}

\begin{abstract}
RESUMO: Relato analítico da criação e do desenvolvimento do ESTAGIAR - Encontro do Estágio de Língua Portuguesa e Literaturas de Língua Portuguesa, evento anual promovido na Universidade Estadual de Londrina pelo Grupo de Pesquisa FELIP - Formação e Ensino em Língua Portuguesa. Como inspiração e parceria de pensares ao longo desse processo, fundamentamo-nos principalmente em Nóvoa (1992) e Tardif (2006), quando olhamos para a formação de professores, em Pimenta e Lima (2008) e Zabalza (2014), ao refletirmos sobre questões gerais do estágio, e em Silva (2012) e Pietri (2018), quando procuramos adentrar nas especificidades do estágio de Língua Portuguesa e Literatura. A trajetória do ESTAGIAR até o momento, expressa nesse artigo, caminha no sentido de aprofundar questões do ensino dentro do estágio e de respondermos, como universidade, a essas questões - seja expondo experiências bem sucedidas, seja ajudando, em parceria com a escola, a trabalhar questões problemáticas. Ao mesmo tempo, entendemos que esse exercício de análise reforça o foco maior da trajetória acadêmica da Área de Metodologia e Prática de Ensino do Departamento de Letras Vernáculas e Clássicas, a que pertencemos, de contribuir para a construção de um pensamento problematizador para as questões de ensino e formação de professores de Língua Portuguesa e Literatura.
\end{abstract}

PALAVRAS-CHAVE: Estágio. Evento. Ensino de Língua Portuguesa e Literatura.

\section{ESTAGIAR: \\ PORTUGUESE LANGUAGE AND LITERATURE INTERNSHIP IN EVENT}

ABSTRACT: This is an analytical account of the starting point and development of ESTAGIAR Portuguese Language and Literature internship meeting, an annual event promoted by the FELIP Research Group - Teacher Education and the Teaching of the Portuguese Language at the State University of Londrina. As an inspiration and partnership for thinking along this process, we mainly draw on Nóvoa (1992) and Tardif (2006), when we look at teacher education; on Pimenta and Lima (2008) and Zabalza (2014), when we ponder on general questions of the internship; and on Silva (2012) and Pietri (2018), when we try to get into the specifics of the Portuguese Language and Literature internship. The taken course of ESTAGIAR so far, expressed in this article, moves towards deepening teaching issues within internship and addressing them, as a university, either by presenting successful experiences, or by helping, in partnership with the school, deal with problematic issues. At the same time, we understand that this screening exercise reinforces the main focus of the academic course of the Methodology and Teaching Practice Area of the Department of

\footnotetext{
${ }^{1}$ Doutor em Educação pela Universidade Estadual de Campinas. Professor associado do Departamento de Letras Vernáculas e Clássicas da UEL, com atuação no Programa de Pós-Graduação em Estudos da Linguagem (PPGEL), no Programa de Mestrado Profissional em Letras (PROFLETRAS), na Especialização em Língua Portuguesa e na Licenciatura em Letras/Português. E-mail: nubio@uel.br

2 Professora no Departamento de Letras Vernáculas e Clássicas do CCH da Universidade Estadual de Londrina. Doutora em Linguagem e Educação pela Universidade de São Paulo. E-mail: sheilalima@uel.br
} 


\section{$=\mathrm{T}$ RAMA $=$}

Vernacular and Classical Letters, to which we belong, which is to contribute to the construction of a problematizing thought for questions of teaching and teacher education of Portuguese Language and Literature.

KEYWORDS: Internship. Event. The Teaching of Portuguese Language and Literature.

\section{INTRODUÇÃO}

Dimensões da prática têm experimentado avanços nas licenciaturas brasileiras nas últimas décadas. Primeiramente, superamos parcialmente um histórico modelo da racionalidade técnica do " $3+1$ " - três anos de disciplinas teóricas, "de conteúdo", mais um ano de formação pedagógica - para a possibilidade de oferta de estágio também no $3^{\circ}$ ano dos cursos. Mais recentemente, implantaram-se as Atividades Práticas como Componente Curricular (APCC) nas diferentes licenciaturas, que não só se fazem presentes ao longo de todo o curso como incentivam as disciplinas, principalmente as "de conteúdo" a explicitarem sua dimensão de prática. Especificamente na licenciatura de Letras-Português da Universidade Estadual de Londrina (UEL), a mais recente reformulação curricular contemplou uma antiga reivindicação da Área de Metodologia e Prática de Ensino de Língua Portuguesa e Literaturas de Língua Portuguesa: disciplinas dentro da grade curricular voltadas especificamente para as demandas do estágio curricular obrigatório, ministradas pelos professores supervisores de estágio ao seu grupo de orientados.

São avanços, todavia, que não podem acomodar os docentes que trabalham nessa área. Professores de Metodologia e Estágio de diferentes cursos vivemos muitas vezes a cotidiana batalha de destacar a relevância das questões de ensino e formação de professores aos olhos das áreas "de conteúdo". Uma batalha que deveria ser desnecessária, por óbvia, já que, lembremo-nos, estamos falando de licenciaturas.

O ESTAGIAR - Encontro do Estágio de Língua Portuguesa e Literaturas de Língua Portuguesa surgiu na continuidade dessa nossa luta, que esperamos esteja se constituindo como um relevante avanço.

Nesse sentido, apresentamos neste artigo um relato da nossa experiência de três anos à frente da coordenação desse evento. Inicialmente, destacamos os estudos em formação de professores e os particulares olhares para o estágio de Língua Portuguesa e Literatura que têm inspirado continuamente o nosso trabalho e colaborado no trabalho de construção e (re)avaliação das edições do ESTAGIAR. Numa segunda etapa, apresentamos as linhas gerais que estruturam o evento. Finalmente, procuramos descrever o desenvolvimento das diferentes edições, expondo encaminhamentos que entendemos acertados ou equivocados.

\section{FORMAÇÃO DE PROFESSORES E ESTÁGIO DE LÍNGUA PORTUGUESA E LITERATURA}

A preocupação com cursos superiores para formação de professores no Brasil começou em 1939, com a criação da Universidade do Brasil, no Rio de Janeiro, em que se incluía a Faculdade Nacional de Filosofia, preparando candidatos ao magistério do ensino secundário e normal - quase dois séculos após o início da discussão sobre escolarização para formação de professores na Europa. Essa diferença temporal se explica em função de sermos, ainda no início do século $X X$, um país economicamente estruturado na agricultura, não demandando mão de obra qualificada, por extensão, nem formação de professores em escolas especializadas (TANURI, 2000). A criação do curso de formação de professores na Universidade do Brasil vem na esteira de um país que rediscute suas velhas oligarquias agrárias e abre espaço também para setores do comércio, administração e serviços, dentre outros. 
A Faculdade de Filosofia formava bacharéis em Pedagogia que, com mais um ano cursando Didática, estavam habilitados a exercer o magistério. É a origem do famoso e já referido " $3+1$ ". Nesse contexto, o estágio era visto como espaço para aplicação dos conhecimentos teóricos e não de aprendizagem profissional.

Partindo desse modelo de estágio, Pimenta e Lima (2008) estudam as linhas gerais dos estágios ao longo da formação inicial de professores no Brasil, identificando quatro tipos: (1) estágio centrado na observação dos professores e imitação dos modelos; (2) estágio centrado nas técnicas; (3) estágio centrado na crítica a tudo que a escola tem; e (4) estágio centrado na pesquisa aliando teoria e prática.

Como bem lembra Geraldi (2010), a licenciatura forma, mas não torna alguém professor. O fato é que apenas na década de 1990 começaram a surgir no Brasil pesquisas que focam a identidade profissional docente, reconhecendo o professor como figura central da complexa realidade que é o seu trabalho, sob a influência dos estudos internacionais de Nóvoa (1992) e Tardif (2006), dentre outros. Para esses pesquisadores, o saber docente se constitui de forma bem mais complexa que creem muitos olhares desavisados, com óbvias reverberações para o desenvolvimento do estágio. Para além do conteúdo das disciplinas "específicas", o saber docente constrói-se também na gestão das interações em sala de aula, dentre outros aspectos. Tardif (2006) apresenta alguns dos saberes profissionais dos professores:

a) os saberes profissionais dos professores são temporais;

b) os saberes profissionais dos professores são plurais e heterogêneos;

c) os saberes profissionais são personalizados e situados;

d) o objeto do trabalho do docente são seres humanos.

Para ele, a desconsideração da existência desses complexos saberes pelos cursos de formação contribui para uma ampliação do distanciamento entre os saberes profissionais e os conhecimentos universitários.

Ainda que de forma tímida, esforços emanados de diferentes instâncias têm procurado sinalizar para uma construção curricular mais atenta a uma maior articulação teórico-prática nos currículos das licenciaturas, com vistas a pelo menos diminuir esse distanciamento. Pudemos comprovar recentemente esse esforço em pesquisa que desenvolvemos, analisando a presença e o desenvolvimento das APCC nas licenciaturas públicas de Letras do Estado do Paraná (MAFRA; MOREIRA; ACRI; FERREIRA, 2019). O reconhecimento da importância do desenvolvimento de atividades práticas ao longo da licenciatura vem junto com a visão de que o estágio não pode mais ser considerado como o único componente responsável pela formação do docente para a efetiva prática em sala de aula (VALSECHI; KLEIMAN, 2014). Na busca de uma melhor caracterização dessa dimensão teórico-prática no universo da formação de professores, Pietri (2018) colabora com as importantes categorizações de "cultura acadêmica" e "cultura escolar".

Atualmente, quando o estagiário de Língua Portuguesa e Literatura parte para a efetiva regência, transparece muito mais a experiência que ele teve como estudante da educação básica do que a perspectiva dialógica e interacionista da linguagem trabalhada no seu curso de Letras.

Neste sentido, as crenças e mitos que o senso comum reproduz aparecem como modelo a ser seguido, que garante êxito, objetividade e facilidade para realizar a avaliação da aprendizagem, haja visto que mensurar questões gramaticais e escolas literárias numa prova é mais visível que perceber o avanço do aluno por meio de uma estratégia de leitura ou a coerência na escrita e na oralidade (SEGABINAZI; LUCENA, 2018, p. 10). 


\section{$=$ TRAMA $=$}

No âmbito do estágio de Língua Portuguesa e Literatura, Angelo (2005) problematiza a abordagem de textos de referência e documentos oficiais que, na linha do tipo de estágio (3) anteriormente referido por Pimenta e Lima (2008), criticam o ensino atual de Língua Portuguesa e Literatura, mas produzem avaliações generalizantes e inspiradas em práticas abstratas. Fugindo dessa prévia visão "criminalizada" do estágio e das práticas dos professores da educação básica, entendemos ser sempre necessário construir uma análise crítica, mas livre de preconceitos, levando em conta a complexidade dos contextos pedagógicos.

Em quaisquer desses cenários, todos os atores envolvidos no processo do estágio consideram o aluno da educação básica como o destinatário das atividades desenvolvidas. Na prática, porém, esse direcionamento acaba não sendo priorizado e o próprio trabalho do estagiário muitas vezes se vê assujeitado, constituindo-se numa mera execução de tarefas, não obstante verificar-se aqui e ali os esforços do estagiário na construção de ações mais propositivas e autorais (HINZ; DI FANTI, 2012). Há riscos de esse processo de assujeitamento no estágio gerar reverberações na vida profissional desses futuros docentes. "Pode-se consolidar, no movimento de precarização da formação docente, um magistério de segunda classe, mão-de-obra barata e pouco qualificada, moldada apenas para atender as demandas de quantitativo de docentes necessários nas escolas" (AGUIAR, 2012, p. 3).

Em vista de todo esse cenário apresentado, entendemos, assim como Silva (2012), que o estágio supervisionado não pode ser a única instância formativa da licenciatura em Letras a trabalhar os saberes docentes orientadores da prática profissional - incluindo aí os procedimentos avaliativos. Outras disciplinas do curso precisam atuar de forma efetiva para a plena construção de uma integração entre teoria e prática. Além disso, precisamos avançar na constituição de um campo próprio de investigação científica, de caráter interdisciplinar, dadas as especificidades do estágio (ZABALZA, 2014).

O lugar diferenciado da prática - e, por extensão, do estágio - expresso de alguma forma em todas essas discussões culminaram com a implantação, em 2018, do atual currículo de Letras-Português da UEL (UEL, 2017). O ESTAGIAR começou a ser gestado no bojo das discussões para criação desse currículo. Os pressupostos teóricos relacionados à formação de professores e ao estágio de Língua Portuguesa e Literatura compõem o DNA desse evento.

\section{CRIAÇÃO E ESTRUTURAÇÃO DO ESTAGIAR}

Londrina é reconhecida como uma cidade universitária. Tal reconhecimento não cancela o fato de que as instituições de ensino superior da região, principalmente as privadas, vêm fechando cursos presenciais de licenciatura, particularmente em Letras. Ao longo das duas últimas décadas, a Universidade Filadélfia (UNIFIL) e a Universidade Norte do Paraná (UNOPAR) fecharam seus cursos de Letras em Londrina, a UNOPAR fechou também o seu curso de Letras em Arapongas e a Faculdade Paranaense (FACCAR) fechou o seu em Rolândia.

Esse fechamento de cursos de Letras reflete-se no fato de que atualmente apenas a UEL oferta curso presencial de Letras/Português na região de Londrina, atendendo em torno de 140 estagiários por ano - não obstante a organização educacional KROTON, a que se vincula atualmente a UNOPAR, ser hoje uma gigante nacional na formação de professores EAD.

Esse foi um dos primeiros fatores que fez com que a Área de Metodologia e Prática de Ensino do Departamento de Letras Vernáculas e Clássicas pensasse na criação de um evento específico do estágio. Mais do que a criação, todavia, buscava-se uma caracterização para o evento que incorporasse os pontos positivos de outros eventos similares, com destaque para o já tradicional SMELP - Seminário de Metodologia de Ensino de Língua Portuguesa, da Faculdade de Educação da Universidade de São Paulo (USP). Ao mesmo tempo, a vasta 
experiência dos professores da área, tanto na supervisão de estágios quanto na participação em eventos em geral, contribuiu para que fosse sendo delineado também o que não se desejava e o que poderia ser feito de forma diferente, mas significativa.

Nesse sentido, uma decisão importante foi que o evento seria pequeno e focado, visando a discussão sobre as práticas de estágio de Língua Portuguesa e Literaturas de Língua Portuguesa, a divulgação de metodologias no âmbito do ensino-aprendizagem de Língua Portuguesa e Literaturas de Língua Portuguesa, o desenvolvimento de um olhar crítico do estagiário de Letras/Português em relação à sua prática docente e o papel da escola, assim como o fortalecimento dos laços com a coordenação de Língua Portuguesa do Núcleo Regional de Educação de Londrina (NRE-Londrina) e os campos de estágio. Juntamente com esses objetivos, busca-se também fortalecer ainda mais a participação política e a reflexão da Área de Metodologia e Prática de Ensino junto ao Departamento de Letras Vernáculas e Clássicas.

O ESTAGIAR é voltado para alunos de estágio da graduação Letras/Português da UEL, egressos do ano anterior da graduação Letras/Português da UEL, professores de Língua Portuguesa e Literaturas de Língua Portuguesa dos campos de estágio, pesquisadores da UEL que trabalhem com o tema "estágio de Língua Portuguesa e/ou literatura" e demais interessados.

Em consonância com perfil de evento pequeno, procura-se focar nas atividades e pesquisas de estágio em Língua portuguesa e Literatura desenvolvidas na própria instituição. Quando dizemos que o foco temático do evento é o estágio, isso significa dizer também que o ESTAGIAR não contempla todas as nuances do ensino e da formação de professores em Língua Portuguesa e Literatura. Não obstante, a comunidade em geral pode participar do evento na condição de ouvinte - com especial atenção e incentivo à participação dos(as) estudantes de Letras das séries anteriores ao estágio.

Uma das formas de atingir o objetivo de fortalecimento da integração com o NRELondrina tem sido o apoio daquele órgão ao evento, através da Coordenação de Língua Portuguesa. Além disso, visamos um aprofundamento da relação com as escolas estaduais, reforçando os laços com os campos de estágio por meio do incentivo à coautoria estagiárioprofessor do campo de estágio.

Entendemos que uma das formas de constituição de olhares críticos de estudantes e professores de campo em relação ao estágio, passa pela construção plena deles como sujeitos nas diferentes instâncias de um evento acadêmico. Com base nessa premissa, uma das marcas do ESTAGIAR é a participação tanto de professores dos campos de estágio quanto estagiários em mesas, coordenação de comunicações etc.

Outra decisão importante e diferenciada foi a disponibilização dos Anais com os textos completos na abertura do evento. Essa decisão implica a necessidade de entrega de trabalho completo antes do evento não só para os participantes das sessões de comunicação como para os convidados das palestras e mesas-redondas. Porém, favorece sobremaneira a interação dos participantes - seja após as palestras, mesas-redondas e comunicações ou até mesmo nas conversas dos intervalos - que se faz academicamente fortalecida na leitura prévia dos textos completos previamente disponibilizados.

Definiu-se também que o evento seria programado dois meses após o início do $2^{\circ}$ semestre letivo. Essa previsão de data de realização foi pensada para poder contemplar os trabalhos produzidos pelos estagiários que cursaram o $1^{\circ}$ semestre letivo, tendo ainda, além do recesso do meio do ano, uma margem de dois meses para produzir e/ou finalizar seus respectivos textos escritos. 


\section{EDIÇÕES DO EVENTO}

O ESTAGIAR realizou, até o momento, três edições, nos anos de 2017, 2018 e 2019, tendo sido interrompida sua periodicidade anual em decorrência da pandemia de Covid-19, que interrompeu todas as atividades presenciais nas universidades, além de efetivar o atraso de um semestre para o prosseguimento do ano letivo de 2020 na UEL.

Ao longo dos três anos de sua realização, o evento sofreu pequenas alterações em seu formato, derivadas das adequações implementadas pelas equipes coordenadoras, como forma de corresponder às demandas registradas nas avaliações de cada uma das edições do evento. Entretanto, é fundamental ressaltar que, em todas as realizações do ESTAGIAR, foram mantidos, rigorosamente, os princípios relativos ao foco temático, ao objetivo e ao público alvo, detalhados na seção anterior.

Ao avaliar o primeiro triênio do ESTAGIAR, é possível considerar um avanço significativo em vários aspectos, dos quais serão foco de análise três deles: impacto (em quantidade e setores atingidos), produção (em quantidade e diversidade de participações) e foco temático. Os dados analisados são oriundos dos registros feitos nos Anais do ESTAGIAR, edições 1, 2 e 3, e dos relatórios de participação, realizados pela Divisão de Eventos da Pró-Reitoria de Extensão da UEL, emitidos a cada uma das edições do evento.

Antes de mergulhar na análise do impacto do evento, lembramos que um dos princípios que norteiam o ESTAGIAR é a efetivação do debate entre ensino superior e educação básica, sendo o estágio um dos campos privilegiados nessa vinculação. Nesse sentido, o público-alvo é constituído, principalmente, por estudantes de licenciatura em Letras e professores da educação básica, polos que têm condições de efetivar o debate a respeito da experiência do estágio, a partir, evidentemente, de olhares distintos e, por essa razão, capazes de conduzir a uma discussão rica e formativa para os setores envolvidos na questão.

Ao longo dos três anos de sua realização, o ESTAGIAR teve uma quantidade significativa de participações, conforme se observa na tabela a seguir:

Tabela 1: Número total de Participantes Inscritos do ESTAGIAR por ano

\begin{tabular}{|c|c|}
\hline Ano & Total de Participantes Inscritos \\
\hline 2017 & 93 \\
\hline 2018 & 118 \\
\hline 2019 & 107 \\
\hline
\end{tabular}

Fonte: Sistematização elaborada pelos autores

Embora haja um decréscimo de participações no ano de 2019, em relação a 2018, é inegável que o evento ganhou, em pouco tempo, uma estabilidade de adesão do público, formado, sobretudo, por estudantes da própria UEL, a quem o evento prioritariamente se destina ${ }^{3}$. Vale ressaltar ainda que os números acima representam a quantidade de participantes com presença acima de $70 \%$ das horas totais do evento, fator que permite uma efetiva referenciação do impacto das atividades, na medida em que se configura a partir de certa permanência do participante ao longo do encontro.

Outro fator de impacto a se observar é o número de comunicações apresentadas em cada uma das três edições do evento, o que evidencia um crescimento do interesse dos

\footnotetext{
${ }^{3}$ Embora o evento se destine, prioritariamente, aos estudantes do curso de licenciatura em Letras da UEL, não há obrigatoriedade da inscrição, visto que esta é paga pelos próprios alunos. As atividades são abertas a todos, mas apenas os inscritos e presentes a 70\% das horas do evento recebem certificação. 
participantes em compartilhar suas experiências. Nesse sentido, observa-se também que o evento foi se constituindo, ao longo dos anos, como um espaço discursivo legitimado pela comunidade acadêmica e educacional (secretarias, escolas etc.).

O crescimento dos números de participações com apresentação de trabalhos ao longo dos anos possibilita avaliar não apenas os efeitos positivos do evento em seu público-alvo, mas também o reconhecimento do ESTAGIAR como espaço efetivo de debate sobre o tema do estágio curricular das licenciaturas em Letras.

A figura a seguir expõe o quantitativo de trabalhos apresentados a cada ano e a origem dos autores - se acadêmicos (licenciandos, docentes, pesquisadores em Letras) ou professores das escolas de educação básica:

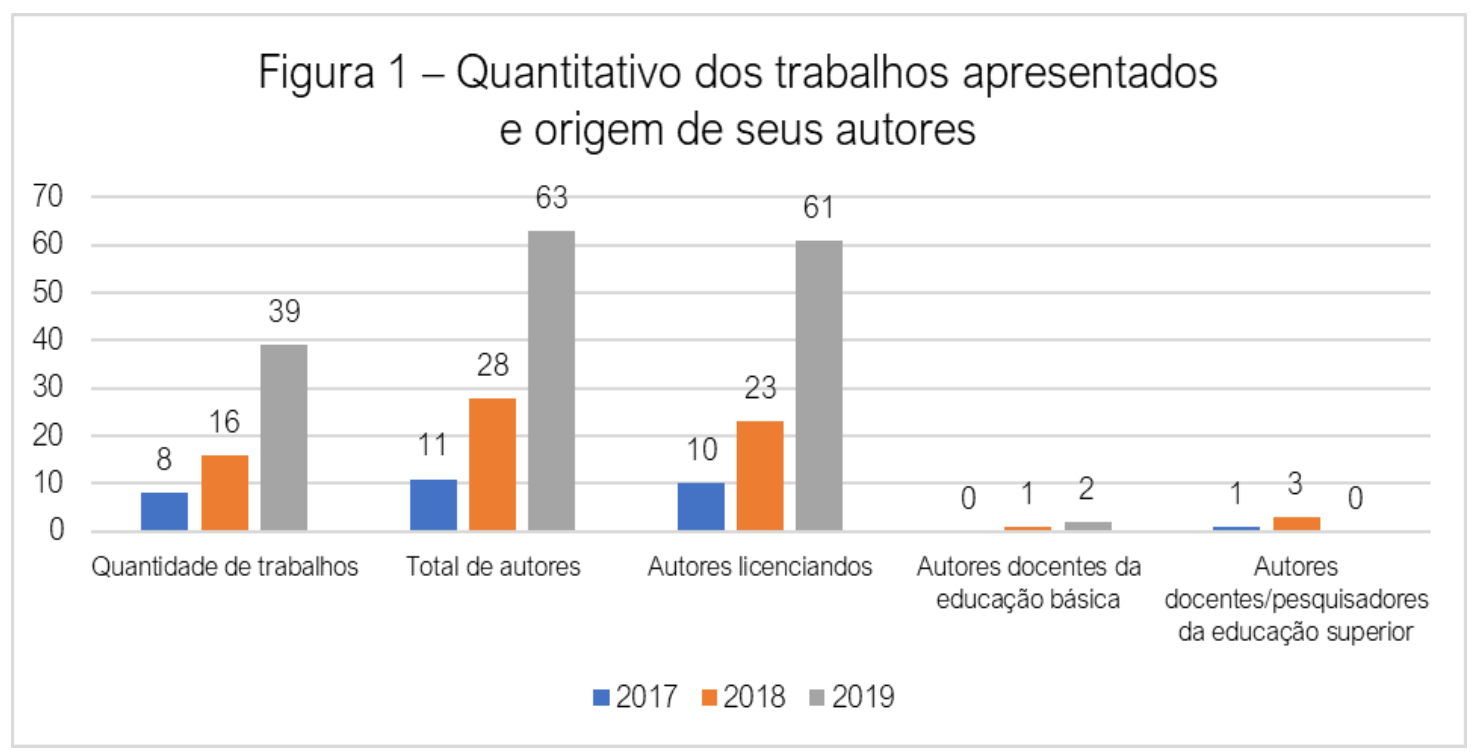

Fonte: Sistematização elaborada pelos autores

Os números expostos na Figura 1 revelam que, ao longo dos três anos, houve aumento significativo na participação com apresentação de trabalhos, com destaque para o último ano de realização do evento. Também se observa que a participação de autorias de estudantes é notadamente mais numerosa que a de docentes/pesquisadores dos cursos de Letras ou de docentes da educação básica. Essa situação decorre, talvez, do fato de haver uma exigência das disciplinas metodológicas para a participação no evento e do acolhimento dos trabalhos apresentados para a composição da avaliação final das disciplinas de estágio. Entretanto, é inegável que o interesse em compartilhar as reflexões em sessões de comunicação demarca também uma maior valorização da própria atividade de estágio, que passa a assumir um estatuto mais acadêmico, já que há espaço para sua disseminação.

Se considerarmos a relação entre o número total de participantes a cada ano e a quantidade de trabalhos apresentados, vemos que há um avanço no reconhecimento do evento enquanto espaço legítimo de debate. Isso se comprova quando observamos que o número de participantes sofre alterações menos significativas, percentualmente, que o número de trabalhos apresentados. Levando em consideração apenas a primeira e a última edições do evento, o crescimento no número de participantes é da ordem de $15 \%$, enquanto o número de trabalhos apresentados tem um salto de mais de $480 \%$.

Embora a quantificação não possa ser tomada como um retrato fiel de certa realidade, não é de todo inadequado considerar que tais crescimentos numéricos podem ser indicativos 
de que o evento ganhou, ao longo de suas edições, reconhecimento e legitimidade, sobretudo no que diz respeito à sua função de disseminador de experiências das práticas de estágio.

Ainda observando o aumento das participações com apresentação de trabalhos e a legitimação do espaço de discussão, chamam a atenção os trabalhos em coautoria entre estudantes de licenciatura e professores das escolas campo. Apesar de se tratar de um número aparentemente irrisório - 1 participante, em 2018, e 2, em 2019 -, a presença de autores docentes da educação básica deve ser destacada no contexto do ESTAGIAR. Em todos os casos, trata-se de trabalhos (num total de 3) em que a parceria entre estagiário e professor da escola campo levou à construção de reflexões conjuntas, que resultaram na produção de artigo e na apresentação de comunicação, efetivando o processo de disseminação das atividades desenvolvidas pelos autores.

Quadro 1 - Trabalhos em coautoria com representantes acadêmicos e docentes da educação básica

\begin{tabular}{|c|c|c|c|}
\hline Ano & Título & Autor Licenciando & $\begin{array}{c}\text { Docente da } \\
\text { Educação Básica }\end{array}$ \\
\hline 2018 & $\begin{array}{l}\text { Narrativas multimodais com } \\
\text { coerência e coesão }\end{array}$ & $\begin{array}{l}\text { Raphael Soares Menten } \\
\text { (UEL) }\end{array}$ & $\begin{array}{c}\text { Cristiane Takahara } \\
\text { (C.E. Jardim Eldorado) }\end{array}$ \\
\hline \multirow[b]{2}{*}{2019} & $\begin{array}{l}\text { O ensino de literatura e a } \\
\text { formação do leitor crítico no } \\
\text { ensino médio }\end{array}$ & $\begin{array}{c}\text { Nara Carvalho (UEL) } \\
\text { Thaylis Manuella Faria (UEL) }\end{array}$ & $\begin{array}{l}\text { Ana Paula da Silva } \\
\text { (C.E. Albino Feijó) }\end{array}$ \\
\hline & $\begin{array}{l}\text { Olimpíada de língua } \\
\text { portuguesa: o documentário } \\
\text { como gênero textual e } \\
\text { instrumento de } \\
\text { (transform)ação social }\end{array}$ & $\begin{array}{l}\text { Danielle Bonifácio da Silva } \\
\text { (UEL) } \\
\text { Vanira de Souza (UEL) }\end{array}$ & $\begin{array}{l}\text { Marcelo Francisco de } \\
\text { Araújo } \\
\text { (C.E. Benedita Rosa } \\
\text { Rezende) }\end{array}$ \\
\hline
\end{tabular}

Fonte: Sistematização elaborada pelos autores

O aspecto fundamental que se observa nesses casos é a concretização de um dos objetivos mais primordiais do ESTAGIAR, isto é, a aproximação entre universidade e escola, numa perspectiva de interação e contribuição mútua para a formação de docentes. Nesse sentido, embora numericamente um tanto tímidas, podemos afirmar que tais realizações confirmam os resultados positivos atingidos pelo evento ao longo de suas edições.

Ainda observando os dados relativos aos trabalhos apresentados, é possível afirmar que, em sua grande maioria, constituem-se a partir de relatos de experiências de estágio, nos quais é possível encontrar as narrativas das vivências, ressignificadas por uma problematização que conta com o apoio de teorias estudadas nas aulas de Metodologia. Os temas são variados e tratam desde aspectos específicos do ensino de língua portuguesa e suas literaturas até temáticas mais gerais da educação, como indisciplina e processos de inclusão. A Figura 2 expõe a distribuição dos diversos trabalhos em seus respectivos domínios temáticos: 


\section{$=$ TRAMA $=$}

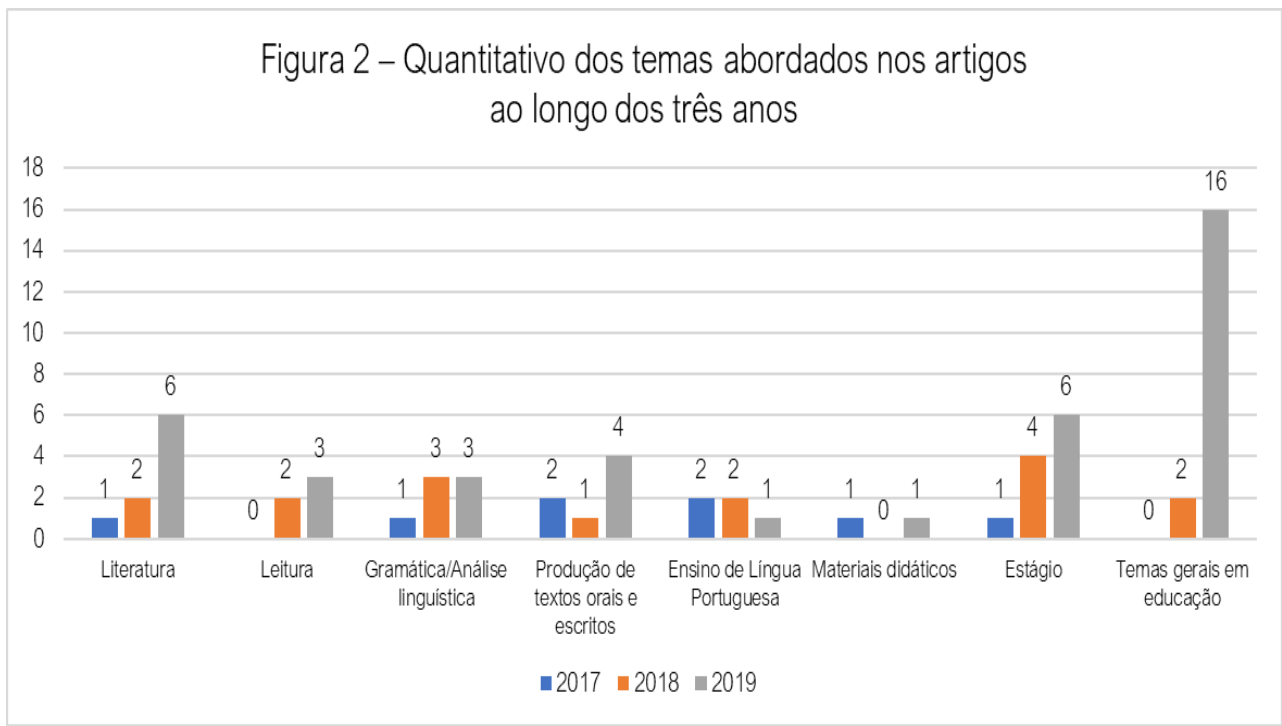

Fonte: Sistematização elaborada pelos autores

A leitura da Figura 2 aponta para diversas situações a serem registradas a respeito do foco temático do evento: o estágio em Língua Portuguesa e Literatura. De um modo geral, considerando os três anos de realização do evento, vemos que a maior parte dos trabalhos apresentados centra-se no âmbito das práticas ligadas ao ensino de Língua Portuguesa, com foco maior em uma ou outra frente de trabalho, sendo que a experiência de estágio não é, nesses casos, o eixo de discussão. Pode-se afirmar que há um total de 33 trabalhos nessas condições ao longo das três edições do evento.

Também se destaca o crescimento, notadamente nos últimos dois anos, do número de trabalhos com foco na experiência de estágio, apesar do número ainda limitado de artigos nessas condições (11). Sobre esse fato deve-se ressaltar que, no primeiro e no segundo ano do evento, as autorias dos trabalhos eram, principalmente, de docentes da própria universidade e de uma pesquisadora do Programa de Pós-Graduação em Estudos da Linguagem. Já em 2019, todos os trabalhos nessa temática eram de autoria dos estudantes do curso de licenciatura em Letras da UEL. Essa alteração pode levar à inferência de que o próprio evento, em suas duas primeiras edições, foi eficaz em dar significado à prática do estágio, elevando-a ao estatuto de tema a ser problematizado pelos próprios estagiários em seu processo de formação docente.

No entanto, se há essa maior atenção ao estágio enquanto tema a ser debatido pelos próprios alunos estagiários, há, na outra face, um crescimento de certa dispersão temática acolhida, em nossa tabela, pelo campo "Temas gerais em educação" - que, apesar de se tratar de problematizações oriundas das vivências realizadas nas práticas de estágio, voltam seu foco para questões de larga abrangência, longe da especificidade do ensino de Língua Portuguesa e Literatura, como inclusão de alunos com TDAH ou de refugiados haitianos, afetividade, cidadania, conhecimentos prévios do aluno, escola pública, NTIC, estratégias de ensino, indisciplina, relação professor-aluno etc.

Não se pode dizer que o estágio não esteja em causa nesses trabalhos nem que o ensino de Língua Portuguesa e Literatura tenha deixado de fazer parte de tais relatos. Entretanto, não se pode afirmar, também, que se trata de reflexões sobre o estágio de Língua Portuguesa e Literatura propriamente, fato que aponta para a necessidade de se observar mais, no trabalho das orientações, a criação de parâmetros melhor delineados para o direcionamento 


\section{$=$ TRAMA $=$}

de uma prática mais focada, que favoreça uma reflexão mais pertinente à área de atuação dos estagiários de Letras.

Por outro lado, não se podem desprestigiar tais reflexões levadas pelos alunos, na medida em que se trata de preocupações da contemporaneidade, relativas à educação e ao ensino e que, em maior ou menor grau, afetam significativamente a sala de aula e, consequentemente, o ensino de Língua Portuguesa e Literatura. Trata-se, portanto de temas que devem ser debatidos e que precisam encontrar territórios em que possam ser discutidos.

Para finalizar, é preciso relembrar que o ESTAGIAR não limita o espaço do debate às atividades de comunicação de trabalhos de alunos, docentes e pesquisadores do estágio em Letras. Conta também com mesas e conferências com foco nas práticas de estágio e similares, como o Programa de Bolsa de Iniciação à Docência (PIBID) e o Programa de Residência Pedagógica.

Ao longo das edições do evento, o formato das atividades de palestra variaram seu formato, sem, no entanto, perder de vista dois focos primordiais: o tema do estágio de Língua Portuguesa e Literatura e a garantia de voz aos envolvidos nas práticas de estágio, seja o professor da educação básica, o licenciando ou o docente/pesquisador da universidade.

No $1^{\circ}$ ESTAGIAR as palestras de abertura e encerramento versaram sobre a importância do estágio curricular supervisionado na formação do docente, enquanto a mesa de debates teve como tema uma questão fundamental, que representa uma das principais metas de problematização do evento: "Universidade e escola: uma parceria?". O $2^{\circ}$ ESTAGIAR, mantendo o foco, trouxe palestras que abordaram novas perspectivas para o campo de estágio, sobretudo no que se refere a estudos teórico-metodológicos da formação docente. A última edição do evento apontou para novas direções, com palestras que revelavam novas possibilidades de práticas de formação docente, como a internacionalização e os programas PIBID e Residência Pedagógica.

\section{CONSIDERAÇÕES FINAIS}

A proposta do ESTAGIAR evidencia um esforço da área de Metodologia da licenciatura em Letras da UEL no sentido de enfrentar situações muito frequentes e historicamente construídas nos cursos de formação docente. Nesses termos, fortalece politicamente as discussões sobre ensino e formação de professores, com destaque para o estágio, expressas em todas as instâncias departamentais de discussão da licenciatura em Letras-Português.

A tentativa de escapar da lógica "3+1" já se verifica no currículo implementado desde 2018, em que as disciplinas metodológicas estão presentes desde os primeiros anos do curso. Nessa esteira, o ESTAGIAR tem tido papel de consolidador de uma nova perspectiva na formação docente, na medida em que, mesmo tendo as disciplinas de estágio concentradas nos últimos anos do curso, expõe ao aluno dos primeiros anos a realidade e as experiências dos estagiários em suas atividades nas escola campo, por meio das sessões de comunicação de trabalhos de seus colegas. Mais que isso, o aluno dos primeiros anos tem acesso a uma problematização em torno da experiência de estágio, o que, certamente, tem seus efeitos na sua formação, desde os primeiros anos do curso. O fato de haver, no último ano do ESTAGIAR, um quantitativo maior de trabalhos que focam na temática do estágio em si pode ser compreendido como o resultado positivo de um percurso de formação marcado pelas discussões realizadas nas edições anteriores do evento.

Ainda considerando a participação dos alunos dos primeiros anos como ouvintes no ESTAGIAR, é possível considerar que o evento promove o contato com práticas concretas 
desde o início do curso, evitando o que Angelo (2005) e Pimenta e Lima (2008) criticam a respeito da fundamentação das licenciaturas centradas em discussões teóricas e abstratas.

Por fim, é preciso também atentar para o fato de que os ganhos do ESTAGIAR não se concentram apenas na formação docente, o que, em si já seria o suficiente para valorar o evento, mas também na sua capacidade agregadora, na relação entre universidade e escola de educação básica, por extensão, teoria e prática. A presença dos docentes da educação básica, embora não tenha se dado ainda de forma maciça, ocorreu de modo significativo, na medida em que compareceram com suas vozes registradas nas autorias de trabalhos que assinam em parceria com os estagiários.

\section{REFERÊNCIAS}

AGUIAR, Denise Brasil Alvarenga. Formação de professores de língua portuguesa: impressões de viagem. Querubim, ano 8, p. 1-9, set. 2012.

ANGELO, Graziela Lucci de. Revisitando o ensino tradicional de língua portuguesa. Tese (Programa de PósGraduação em Linguística Aplicada), Instituto de Estudos da Linguagem, Universidade Estadual de Campinas, 2005.

GERALDI, João Wanderley. A aula como acontecimento. São Carlos: Pedro \& João Editores, 2010.

HINZ, Josiane Redmer; DI FANTI, Maria da Glória Corrêa. A atividade do professor-estagiário de língua portuguesa: aprendizagem de gêneros profissionais? Letras, Santa Maria, v. 22, n. 44, p. 55-83, jan./jun. 2012.

MAFRA, Núbio Delanne Ferraz; MOREIRA, Vladimir; ACRI, Marcelo Cristiano; FERREIRA, Beatriz do Prado. Quando a prática se torna componente curricular dos PPPs de Letras. In: CAMPONES, Kelly Cristina (org.). Ensino e aprendizagem como unidade dialética. Ponta Grossa: Atena, 2019. p. 410-416.

NÓVOA, António. Vidas de professores. Lisboa: Porto Editora, 1992.

PIETRI, Émerson de. A formação do professor entre a escola e a academia: o estágio supervisionado em ensino de língua portuguesa/língua materna. In: BARZOTTO, Valdir Heitor; PIETRI, Émerson de (orgs.).

Estágio, escrita e formação. Campinas: Mercado de Letras, 2018. p. 13-30.

PIMENTA, Selma Garrido; LIMA, Maria Socorro Lucena. Estágio e docência. 3. ed. São Paulo: Cortez, 2008. SEGABINAZI, Daniela Maria; LUCENA, Josete Marinho de. Estágio supervisionado na formação do professor de Língua Portuguesa: desafios e possibilidades. In: CONGRESSO NACIONAL DE FORMAÇÃO DE PROFESSORES E CONGRESSO ESTADUAL PAULISTA SOBRE FORMAÇÃO DE EDUCADORES, 4. 14., Lindóia, Anais [...] UNESP, 2018. p. 1-11.

SILVA, Wagner Rodrigues. Estudos do letramento do professor e formação inicial nos estágios supervisionados das licenciaturas. In: SILVA, Wagner Rodrigues (org.). Letramento do professor em formação inicial: interdisciplinaridade no estágio supervisionado da licenciatura. Campinas: Pontes, 2012. p. 27-49. TANURI, Leonor Maria. História da formação de professores. Revista Brasileira de Educação, n. 14, p. 61-88, maio/ago. 2000.

TARDIF, Maurice. Saberes docentes e formação profissional. 6. ed. Petrópolis: Vozes, 2006.

UEL. Conselho de Ensino, Pesquisa e Extensão. Resolução CEPE/CA n 142/2017: reformula o Projeto Pedagógico do Curso de Letras Português - Modalidade: Licenciatura - Habilitação: Língua Portuguesa e Respectivas Literaturas, a ser implantado a partir do ano letivo de 2018. Londrina, 6 dez., 2017.

VALSECHI, Marília Curado; KLEIMAN, Angela Bustos. O estágio supervisionado e a voz social do estagiário. Raído, v. 8, n.15, p. 13-32, jan./jun. 2014.

ZABALZA, Miguel A. O estágio e as práticas em contextos profissionais na formação universitária. São Paulo: Cortez, 2014. 